\title{
Clinical study on the impact of long-term survival quality in 204 postoperative patients with breast cancer by cox proportional hazard models
}

\author{
Bei Liu ${ }^{1}$, Qiong Dai ${ }^{1}$, Yukai Du ${ }^{1}$, Xueqing Jiang ${ }^{2}$, Gujun Zhou ${ }^{2}$ \\ ${ }^{1}$ Department of Maternal and Children Health Care and Adolescent Hygiene, School of Public Health, Tongji Medical College, \\ Hua Zhong University of Science and Technical, Wuhan, 430030, China \\ ${ }^{2}$ Thyroid and Breast Surgery, Wuhan Central Hospital \\ Email: duyukai100@yahoo.com.cn; Guoguo761225@163.com
}

Received 19 April 2011; revised 10 May 2011; accepted 12 May 2011.

\begin{abstract}
The aim of study was to evaluate clinical characteristics, social support and the association with the prognosis of breast cancer patients. A total of 204 participants were followed from 2003 until the end of 2008. Information about patients with breast cancer was submitted by investigators. Data were analyzed by Cox's proportional hazard model. The clinical staging of breast cancer we used was the TNM classification. A "T" score is based upon the size and/or extent of invasion. The " $N$ " score indicates the extent of lymph node involvement. Age at diagnose was associated with protective factors $(\mathrm{HR}=0.972$; 95\%CI (0.834 - 1.130)), $\mathrm{T}$ staging (HR = 2.075; 95\%CI (1.424 - 3.022)), N staging (HR = 1.513; 95\% CI (1.066 - 2.148)), were associated with risk factor. Two survival graphs of nodes with negative effects by histology and nodes with positive effects by histology was analyzed by log-rank test, there was statistically significant relationship between two survival graphs $\left(x^{2}\right.$ $=136.8467, p<0.0001)$. Age at diagnoses, Clinical stage tumor and node could contribute to the development of breast cancer and disease free survival in Chinese women.
\end{abstract}

Keywords: Survival quality; Breast Cancer; Postoperative; Cox Proportional Hazard Models

\section{INTRODUCTION}

Several well-established factors have been associated with the prognosis of breast cancer such as size of tumour, lymph node involvement, histological type, oestrogen and progesterone receptor status, and so on. With modern medical model transforming from biomedical model to biology-psychology-community medical model, the ther- apy no longer simply emphasize elimination of tumor and prolongation of life span, at the same time, the improvement of the quality of life is emphasized as well [1]. Owing to the fact that success of treatment in prolonging life is a mixed blessing-it is not enough to survive, patients also want to live [2]. Quality of life (QoL) is currently an important factor in oncological research [3]. QoL and its components and determinants have received growing interest [4-8], and physical, mental and social well-being, with varying levels of emphasis and in various combinations, have been included in the concept $[2,4,9,10]$. As a whole, women who remain free of breast cancer seem to have levels of functioning and QoL that are comparable to those of the general female population, although those who receive systemic adjuvant chemotherapy may do less well [11]. As a result, study for patients' QoL is being emphasized. At the same time, we also hypothesized that women with greater social-emotional support would also survive longer when compared with women with less or no support. Therefore, we explored other potential barriers to patients. By assessing its associations with demographic and clinical characteristics and social support (given retrospective evidence of its positive relationship with participation). The aim of our study was to evaluate clinical characteristics, social support and the association with the prognosis of breast cancer patients. Our study pulled 21 factors about clinical pathology and lifestyle into Cox model which may influence postoperative patients with breast cancer to make clinical synthetic evaluation and analysis in order to improve their QoL and get long-term survival.

\section{METHODS}

\subsection{Participants}

Women aged 23-82 years, diagnosed with a first pathol- 
ogically confirmed breast cancer between January 2000 and February 2001, were identified through three hospitals, including Tongji Hospital, Xiehe Hospital and Wuhan Central Hospital in Wuhan city of China. These hospitals were requested to provide complete information for all known cases of female breast cancer. All patients who entered the study in May 2003 have been received follow-up visit till June, 2008. All of documents included 163 completed data cases and 41 censored cases, which had 25 visit loss cases, 1 death of other diseases case and 15 survival cases.

\subsection{Data Collection}

On the basis of all sources of information, we reconstructed a detailed medical history for each patient. In compiling all sources of information, we also ascertained breast cancer stage, histology, estrogen receptor (ER) status, methods of treatment, age at diagnosis, gestagenic history, and married status [12] through their abstraction of pathology reports and medical records relating to breast cancer diagnosis. For women who had two or more primary cancers diagnosed within the follow-up time, we took the earliest diagnosis, or if both tumors were diagnosed on the same date, the tumor characteristics are those associated with the larger tumor.

Although we were able to confirm most exposure histories of patients through interview of medical records, we were unable to confirm other information. Thus, the exposure information, such as educational level, occupation, emotional function, social function and economical status correlated with health, were obtained by trained interviewers that asked patients, their husband or firstdegree relatives. All data were collected with a standardized questionnaire using a telephone interview. Variables included demographics, emotional function, social function and economical status. If patients die, interviewers must obtain their age at death. Due to the nature of the data collected (medical records and telephone interview), complete information was impossible for some of the variable assessed. In some instances (e.g. the history of other chronic disease, emotional function, social function and economical status) over $35 \%$ of the data were missing, therefore these variables were excluded from the analysis. In the end, complete information was available for 204 cases from the initial study population of 300 cases.

\subsection{Statistical Methods}

Twenty-one features of patients, clinical pathologic factors and lifestyle have been selected as the indexes of analysis and been quantified, which came from clinical records and may influence prognosis of patients with breast cancer. Patients' live time were calculated by month, which means the time span from the operation day to death or termination of follow-up visit, and we put corresponding data of every patient into computer on the basis of clinical records and results of follow-up visit, and data was dealt by SAS9.0 for WINDOWS software and the survival rate was calculated by life table method. All indexes of survival rate difference were analyzed by multiple factor Cox proportional hazard model (using gradually backward progressive method, two-tailed $\alpha=$ $0.05)$.

\section{RESULTS}

The 17 categorical variables were summarized in Table 1. For the model selection there were records with missing variables. Previous analysis on these datasets suggested that missing variables might be informative. Therefore, any missing values in the 17 categories were coded as a separate attribute.

The distributions of various demographic, reproductive and medical characteristics of the cohort were provided in Table 2. Among the 204 women included in this analysis, $48.04 \%$ had at least a college degree, $13.24 \%$ had a first-degree family history of breast cancer and $83.33 \%$ had biopsy for benign breast cancer. The majority was later-stage cancers, and 190 (93.14\%) had infiltrating type.

Multivariate Cox proportional hazard model analysis was showed in Table 3. On the level of $\alpha=0$. 05, it was indicated by analytic results that outstanding factors including age at diagnosis, $\mathrm{T}$ staging, $\mathrm{N}$ staging, emotional function, the level of the hospital, may influence survival time statistically. Age at diagnosis was protective factors (coefficient of regression was negative), the rest were all risk factor (coefficient of regression was upright).

Survival analysis of clinical stage nodes was showed in Figure 1. Two survival graphs of nodes found negative by histology and nodes found positive by histology were analyzed by log-rank test, there was statistically significant relationship between two survival graphs $\left(x^{2}\right.$ $=136.8467, \mathrm{p}<0.0001)$.

\section{DISCUSSION}

Age at diagnosis is one of the most definitive risk factors on breast cancer. Sixty-five percent of all breast cancers occur in women aged 55 and older. Our study found that age at diagnosis was one of prognostic factors. The younger patients at diagnosis showed lower death hazard (Hazard Ratio: 0.972). But none of the prior studies showed that age was one of the prognostic factors, and it is difficult to hypothesize why age at diagnoses would be more closely related to survival time. We presume that the younger patients at diagnose may have fewer chance of developing other chronic diseases and be more 
Table 1. 17 items of survival analysis index and quantification.

\begin{tabular}{|c|c|c|}
\hline Variable & index & quantification \\
\hline $\mathrm{X} 1$ & Age at diagnosis & Years of age \\
\hline $\mathrm{X} 2$ & Years of education & $\begin{array}{l}\text { High school or less }=1 \text { high school graduate }=2 \\
\text { college graduate or higher }=3\end{array}$ \\
\hline $\mathrm{X} 3$ & Married status & Married $=0 \quad$ single $=1$ \\
\hline $\mathrm{X} 4$ & Occupation & Mental labor $=0 \quad$ manual labor $=1$ \\
\hline $\mathrm{X} 5$ & Gestation during breast cancer & No $=0 \quad$ yes $=1$ \\
\hline $\mathrm{X} 7$ & Age at menopause & $\leq 40=1 \quad 41-45=2 \quad 46-50=3 \quad \geq 51=4$ \\
\hline $\mathrm{X} 8$ & $\begin{array}{l}\text { Family history of breast cancer in first- } \\
\text { degree relative }\end{array}$ & No $=0 \quad$ yes $=1$ \\
\hline X9 & Previous biopsy for benign breast cancer & No $=0 \quad$ yes $=1$ \\
\hline $\mathrm{X} 10$ & Other chronic disease & No $=0 \quad$ yes $=1$ \\
\hline $\mathrm{X} 11$ & Histology & In situ $=0 \quad$ infiltrating type $=1$ \\
\hline $\mathrm{X} 12$ & Clinical stage tumor & $\mathrm{T} 1=0 \quad \mathrm{~T} 2=1 \quad \mathrm{~T} 3=2 \quad \mathrm{~T} 4=3$ \\
\hline $\mathrm{X} 14$ & Clinical stage metastasis & $\mathrm{M} 0=0 \quad \mathrm{M} 1=1$ \\
\hline $\mathrm{X} 15$ & Pathology differentiation & $\begin{array}{l}\text { Well-differentiated }=1 \text { moderately differentiated }=2 \\
\text { poorly differentiated }=3\end{array}$ \\
\hline $\mathrm{X} 16$ & Methods of treatment & $\begin{array}{l}\text { Surgical }=1 \quad \text { surgical }+ \text { chemotherapy }=2 ; \text { Surgical }+ \text { chemother- } \\
\text { apy }+ \text { radiotherapy }=3 ; \text { no accept any treatment }=4\end{array}$ \\
\hline $\mathrm{X} 17$ & Hormonal dependent (ER, PR detection result) & Entirely masculine $=1$ partly masculine $=2$ entirely negative $=3$ \\
\hline
\end{tabular}

Table 2. Distributions of demographic, reproductive and medical factors $(n=204)$.

\begin{tabular}{|c|c|c|}
\hline Characteristic & & N (\%) \\
\hline \multicolumn{3}{|l|}{ Age at diagnosis } \\
\hline$\leq 40$ years & 36 & $(17.65 \%)$ \\
\hline $41-50$ years & 36 & $(17.65 \%)$ \\
\hline$\geq 51$ years & 132 & $(64.70 \%)$ \\
\hline \multicolumn{3}{|l|}{ Years of education } \\
\hline High school or less & 65 & $(31.86 \%)$ \\
\hline High school graduate & 41 & $(20.10 \%)$ \\
\hline College graduate or higher & 98 & $(48.04 \%)$ \\
\hline \multicolumn{3}{|l|}{ Married status } \\
\hline Married & \multicolumn{2}{|c|}{$141(69.12 \%)$} \\
\hline Single & 63 & $(30.88 \%)$ \\
\hline \multicolumn{3}{|l|}{ Occupation } \\
\hline Mental labor & \multicolumn{2}{|c|}{$105(51.47 \%)$} \\
\hline Manual labor & 99 & $(48.53 \%)$ \\
\hline \multicolumn{3}{|l|}{ Menopausal status } \\
\hline Pre-menopausal & 97 & $(47.55 \%)$ \\
\hline \multicolumn{3}{|l|}{ Age at menopause } \\
\hline$\leq 40$ years & 15 & $(7.35 \%)$ \\
\hline $41-45$ years & 58 & $(28.43 \%)$ \\
\hline $46-50$ years & 99 & $(48.53 \%)$ \\
\hline$\geq 51$ years & 32 & $(15.69 \%)$ \\
\hline \multicolumn{3}{|l|}{ Family history of breast cancer in first-degree relative } \\
\hline No & 177 & $(86.76 \%)$ \\
\hline Yes & 27 & $(13.24 \%)$ \\
\hline \multicolumn{3}{|l|}{ Previous biopsy for benign breast cancer } \\
\hline No & 34 & $(16.67 \%)$ \\
\hline Yes & 170 & $(83.33 \%)$ \\
\hline \multicolumn{3}{|l|}{ Histology } \\
\hline In situ & 14 & $(6.86 \%)$ \\
\hline Infiltrating type & 190 & $(93.14 \%)$ \\
\hline Partly masculine & 48 & $(23.53 \%)$ \\
\hline Entirely negative & 57 & $(27.94 \%)$ \\
\hline
\end{tabular}


B. Liu et al. / Open Journal of Preventive Medicine 1 (2011) 8-12

Table 3. Multivariate Cox proportional hazard model analysis.

\begin{tabular}{lccccc}
\hline \multicolumn{1}{c}{ Variable } & Parameter Estimate & SE & HR $(95 \% \mathrm{Cl})$ & $x^{2}$ & $\mathrm{P}$ \\
\hline Age at diagnose & -0.02829 & 0.00770 & $0.972(0.834-1.130)$ & 13.506 & 0.0002 \\
T staging & 0.72984 & 0.19196 & $2.075(1.424-3.022)$ & 14.456 & 0.0001 \\
N staging & 0.41402 & 0.17879 & $1.513(1.066-2.148)$ & 5.362 & 0.0206 \\
\hline
\end{tabular}

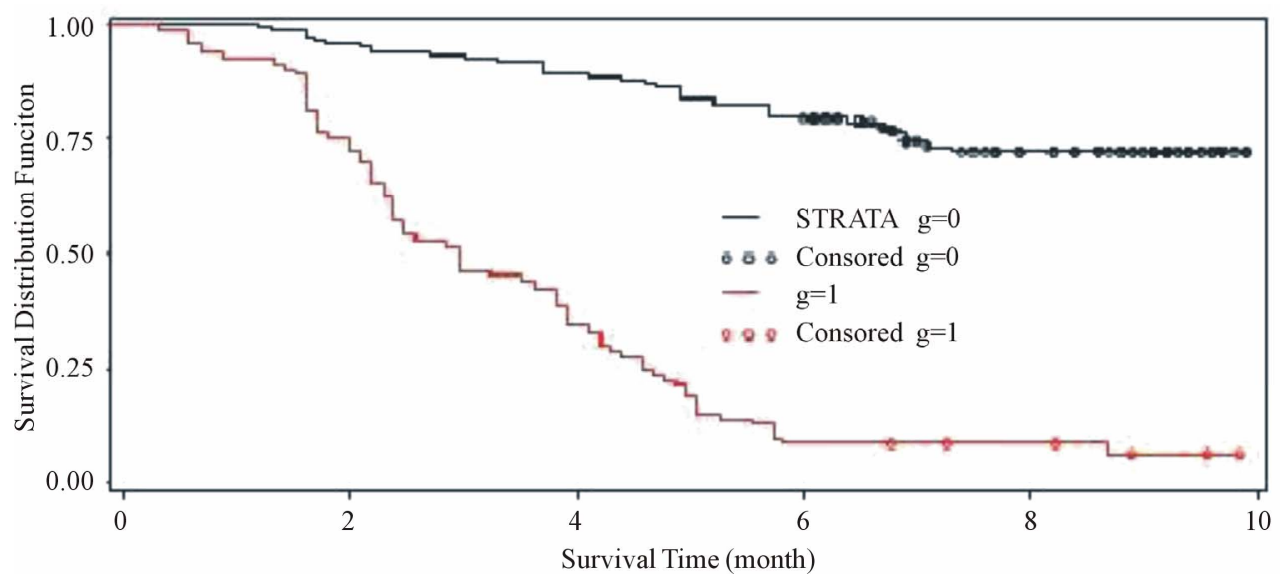

Figure 1. Survival analysis of clinical stage nodes.

healthy than elder patients so that they can survive longer. Further studies are needed to confirm these findings, given that this is the first study to report these associations of breast cancer patients.

Tumor size and clinical stage nodes are two of the most important prognostic factors, although tumor grade may modify this risk assessment. Most commonly used indexes of clinic to evaluate its prognosis referred to TMN staging system and degree of tumor pathology [13], which reflects pathological anatomic scope and histological transformation affecting prognosis. In general, women who have a tumor that measures less than $1 \mathrm{~cm}$ with negative axillary lymph nodes have a greater than $95 \%$ chance of a 10-year disease-free survival. As the tumor size approaches $2 \mathrm{~cm}$, the chance of being disease free within 10 years drops to about 70\% [13]. Previous studies had indicated the relationship between clinical stage tumor, clinical stage nodes and prognosis. Our study also found that HR of T4 was 2.075-fold higher than T1 and Hazard Ratio of N3 was 1.513-fold higher than N0. Moreover, we analyzed two survival graph in different clinical stage nodes because clinical stage nodes as Variable was entered firstly into Cox proportional hazard model, and the analysis result of log-rank test of survival graph showed that there was statistically significant relationship between two survival graphs $\left(x^{2}\right.$ $=136.8467, \mathrm{p}<0.0001)$. Thus, we conclude that clinical stage tumor and clinical stage nodes are two of the most important prognostic factors and the patients of nodes removed indicated lower survival than no nodes found clinically or node negative by histology.

In summary, our results suggest that age at diagnoses, Clinical stage tumor and node could contribute to the development of breast cancer and disease free survival in Chinese women.

\section{LIMITATIONS}

After interpreting the results of this study, it is important to acknowledge its limitations. A limitation of this study was the small, cross-sectional sample related to reported frequencies of symptoms, yet the size of the sample is consistent with qualitative inquiry. Another limitation is participants' recall of their symptoms and information and support needs during the 5 years following therapy. The primary exposures of interest include early-life events, and given that some women in participants are older than 50 years, recall of exact events may have been poor for some women resulting in exposure misclassification. The resultant bias would be non-differential, given that a cohort design was used and, thus would lead to underestimations of the true relative risks. Finally, we were only able to include $68 \%$ of the potentially eligible women in this study because $32 \%$ confounder data were missing. Given the prospective nature of this study these exclusions are unlikely to bias our results. Some variables, such as Hormonal dependent (ER, PR detection result), Family history of breast cancer in first-degree relative, Menopausal status are not internalized into the COX function, but they could be further researched on the basis of expanded sample in future. 


\section{ACKNOWLEDGMENTS}

This work was supported by grants from Tongji Hospital, Xiehe Hospital and the Wuhan Central Hospital. We thanks the help of Professor Ping Yin in data analysis and Assistant Professor Ping Wang in rectifying the manuscript.

\section{REFERENCES}

[1] Gai, X., Fan, Z. and Bresson, J..(1995) Comparison of survival among patientswith breast cancer treated at first teaching hospital, Changchun, China, and Saint-Sacrement Hospital, Quebec, Canada. Chinese Journal Cancer Research, 7(3), 197-205. doi:10.1007/BF03023474

[2] McDowell, I. and Newell, C.. (1996) Measuring Health. A Guide to Rating Scales and Questionnaires, 2nd edition. New York: Oxford University Press, 354-355.

[3] Lehto, U.S., Ojanen, M., and Kellokumpu-Lehtinen, P.. (2005) Predictors of quality of life in newly diagnosed melanoma and breast cancer patients. Ann Oncol, 16(5), 805-816. doi:10.1093/annonc/mdi146

[4] Batel-Copel, L.M., Kornblith, A.B., Batel, P.C. and Holland, J.C.. (1997) Do oncologists have an increasing interest in the quality of life of their patients? A literature review of the last 15 years. European Journal of Cancer, 33(1), 29-32. doi:10.1016/S0959-8049(96)00414-5

[5] Velikova, G., Stark, D. and Selby, P.. (1999) Quality of life instruments in oncology. European Journal of Cancer, 35(11), 1571-1580. doi:10.1016/S0959-8049(99)00193-8

[6] Osoba, D.. (1999) What has been learned from measur- ing health-related quality of life in clinical oncology. European Journal of Cancer, 35(11), 1565-1570. doi:10.1016/S0959-8049(99)00192-6

[7] Curt, G.A.. (2001) Fatigue in cancer. BMJ, 322(7302), 1560. doi: $10.1136 /$ bmj. 322.7302 .1560

[8] Trask, P.C., Paterson, A.G., Hayasaka, S., Dunn, R.L., Riba, M., and Johnson, T.. (2001) Psychosocial characteristics of individuals with non-stage IV melanoma. Journal Clinical Oncology, 19(11), 2844-2850.

[9] Moinpour, C.M., Feigl, P., Metch, B., Hayden, K.A., Meyskens, F.L.Jr. and Crowley, J.. (1989) Quality of life end points in cancer clinical trials: Review and recommendations. Journal National Cancer Institute, 81(7), 485-495. doi:10.1093/jnci/81.7.485

[10] Osoba, D.. (1994) Lessons learned from measuring healthrelated quality of life in oncology. Journal Clinical Oncology, 12(3), 608-616.

[11] Caroline, B., Victoria, C., Sharon, L., Jill, G., Michael, R. and Amanda R.. (2005) Depression and anxiety in women with early breast cancer: five year observational cohort study. BMJ, 330(7943), 698-702.

[12] Furberg, H., Millikan, R., Dressler, L., Newman, B. and Geradts, J.. (2001) Tumor characteristics in African American and white women.. Breast Cancer Res Treat, 68(1), 33-43. doi:10.1023/A:1017994726207

[13] Kwan, W., Jackson, J., Weir, L.M., Dingee, C., McGregor, G. and Olivotto, I.A.. (2002) Chronic arm morbidity after curative breast cancer treatment: prevalence and impact on quality of life. Journal Clinical Oncology, 20 (20), 4242-4248. doi:10.1200/JCO.2002.09.018 